\title{
Além do acaso estúpido da química: o informe como manipulação do tempo em Decasia: the state of decay, de Bill Morrison
}

\author{
Alexandre Rodrigues da Costa ${ }^{1}$, Miriam Aparecida Mendes ${ }^{2}$
}

${ }^{1}$ Alexandre Rodrigues da Costa possui graduação em Letras pela Universidade Federal de Minas Gerais (1997), mestrado em Letras pela Universidade Federal de Minas Gerais (2001), com a dissertação "A construção do silêncio: um estudo da obra poética de Orides Fontela", e doutorado em Letras pela Universidade Federal de Minas Gerais (2005), com a tese "A transfiguração do olhar: um estudo das relações entre literatura e artes plásticas em Rainer Maria Rilke e Clarice Lispector". Atualmente, é Professor de Educação Superior da Escola Guignard da

Universidade Estadual do Estado de Minas Gerais, onde ministra disciplinas relacionadas à História da Arte, desenvolve pesquisas sobre o cinema experimental e sobre a obra do artista alemão Hans Bellmer. e-mail: rodriguescosta@hotmail.com

${ }_{2}^{2}$ Miriam Aparecida Mendes possui bacharelado em Artes pela Escola Guignard (Universidade do Estado de Minas Gerais). Atualmente, é estudante do curso de Licenciatura da Escola Guignard da Universidade do Estado de Minas Gerais, onde participa do programa de iniciação científica. 


\section{Resumo}

Este artigo analisa o filme Decasia: the state of decay, de Bill Morrison, com o propósito de perceber de que maneira o informe pode ser pensado como desarticulação do tempo a partir da apropriação de imagens deterioradas, fragmentadas. Busca-se, assim, pesquisar um cinema cuja duração é a de uma memória que não se prende a um ponto determinado no tempo, mas desmorona a partir do dilaceramento que provoca em si mesma, ao afirmar a precariedade que a mantém.

Palavras-chave: Cinema experimental; Found footage; Informe; Descontinuidade.

\section{Abstract}

This article analyzes Decasia: the state of decay, a film by Bill Morrison, in order to understand how the formless can be considered a disruption of time via the appropriation of deteriorated and fragmented images. Thus, the aim is to analyse a filmmaking whose duration is that of a memory not tied to a particular point in time, but that collapses from the way it tears itself appart when asserting how precarious it.

Keywords: Experimental cinema; Found footage; Formless; Discontinuity. 
Bill Morrison nasceu em 1965, na cidade de Chicago. Graduou-se em artes, em 1989, pela Cooper Union School of Art. Lá, teve aulas com o animador Robert Breer que, além de cineasta experimental, pintor e escultor, participou do cenário vanguardista americano, na década de 50. Quando era estudante de artes, Morrison teve contato com a companhia de teatro Ridge Theater, de Nova York, onde trabalhou para a equipe, fazendo filmes semiabstratos para serem incorporados às performances. Sua primeira produção no cinema experimental data de 1990, com o filme Night Highway.

Como prática de cinema, Morrison utiliza a found footage, que é a apropriação de imagens de filmes existentes com o propósito de, ao inseri-las em um novo contexto, levar-nos a reconhecê-las, a partir desse momento, como imagens recicladas: "imaginar os pedaços originais do filme em novas formas que os distinguem como algo ao mesmo tempo familiar e exótico, contínuo e ruinoso, intangível e inter-relacionado". (VERRONE, 2012, p. 167). Morrison se detém, especificamente, nas películas em estado avançado de deterioração para compor sua obra. Até 1950 , o filme de $35 \mathrm{~mm}$ era composto por uma tira de nitrato de celulose, uma camada de gelatina, e uma emulsão de sais de prata e, somente a partir de 1951, este material orgânico altamente instável, inflamável e de rápida deterioração foi substituído por filme sintético de poliéster. A decadência física do filme de nitrato é um fenômeno que causa a decomposição e desaparecimento das imagens de forma inevitável.

Em suas intervenções, Bill Morrison remonta as imagens e as desvia de suas narrativas, mais interessado nas novas possibilidades de significações e associações que as imagens, com uso da interação e as interferências das corrosões orgânicas causadas pelo tempo, podem oferecer. Dessa forma, seus filmes apontam para e refletem sobre a ação do tempo e a destruição física do material. Isso fica evidente em um dos seus primeiros filmes, The film of her (1996), no qual foram usadas impressões de trechos de filmes artísticos, científicos e imagens de Reclaiming American: History from Paper Rolls by the Renovare Process (Kemp Niver, 1954), cedidas pela Biblioteca do Congresso, em Washington. A temática de The film of her baseia-se na história de Howard L. 
Walls, um funcionário da biblioteca do congresso que recorda seu trabalho na seção de direitos autorais, seu fascínio pelo cinema e sua descoberta das cópias dos filmes em papel em 1942. Essas impressões em papel (paper prints) começaram a ser feitas em 1894, quando Thomas A. Edison passou a copiar os fotogramas dos seus filmes de quinetoscópio e a registrá-los como fotografias individuais. Elas eram feitas sobre cada frame dos filmes e serviam para garantir os direitos dos autores sobre suas obras, já que não havia nenhuma lei que garantisse isso para as imagens de celuloide em movimento. Assim, a Biblioteca do Congresso, em Washington, passou a ser o lugar onde as impressões de papel dos primeiros filmes, do período de 1894 a 1912, ficaram registradas. Com o começo da Segunda Guerra Mundial, o trabalho de preservação dos filmes foi interrompido para dar lugar ao arquivamento do que era apreendido com o inimigo.

A relação de Bill Morrison com o cinema pode ser rastreada até as origens daquilo que alguns teóricos convencionaram chamar de primeiro cinema, período compreendido entre os anos de 1894 e 1908. Filmes como Annabelle butterfly dance (Dickson, 1895) e La sortie des usines Lumière (Louis Lumière, 1895) pertencem a um tempo no qual o cinema se definia como um espetáculo de atrações, cujas principais características eram o sincrético, o apresentativo e o não linear. De acordo com Costa, "os primeiros filmes eram formas abertas de relato e a coerência narrativa não era inerente aos filmes, mas estava no ato de apresentação e recepção". (COSTA, 2012, p. 25). O que liga os filmes de Bill Morrison a essas primeiras obras passa pela busca do cinema por sua linguagem própria, que se articulou em um cinema narrativo, mas que, ao mesmo tempo, manteve-se de forma anárquica em cineastas cujas obras apontam para o questionamento de sua construção artística e do cinema como parte de uma indústria cultural.

Algumas dessas características, que definem o primeiro cinema, são percebidas em boa parte dos filmes de Morrison, uma vez que o cineasta se propõe a romper com as narrativas cinematográficas tradicionais. Ao justapor fragmentos diversos em uma mesma película, Morrison acaba por dar ênfase ao 
estranhamento provocado pela transição de sequências, visto que seu objetivo não é construir narrativas baseadas no modelo de decupagem clássica, mas privilegiar a descontinuidade. Sua opção por fragmentos deteriorados, de certa forma, leva à desconstrução e à decomposição da imagem cinematográfica, no que diz respeito a ela se constituir como ilusão de continuidade com o mundo real. Com base nessas estratégias, "o espectador é compelido a olhar para tomadas familiares como se não as tivessem visto antes, ou pelos quais a mente do espectador torna-se mais alerta para os significados mais amplos do material". (WEE, 1993, p. 36). Nesse sentido, a found footage nos leva a refletir sobre como ela se constitui, ao tornar possível analisar as formas de construção e manipulação das imagens.

The film of her é uma obra que busca esse tipo de participação do espectador. O curta-metragem inicia-se com a imagem de um rolo de filme sendo retirado da prateleira. Logo a seguir, um sujeito, debruçado sobre uma mesa, é acordado. Vemos, então, uma lanterna mágica e, na sequência, imagens referentes ao universo, ao planeta Terra e ao desenvolvimento da vida nele. Acompanhamos a formação do filme em ordem retrocessa, para depois termos o processo de forma linear, com corte de árvores, fabricação de rolos de papel para impressão e a produção de celuloide. Toda essa sequência se apresenta como um ciclo, a partir do qual é possível perceber a vida em seu início e fim, sua ascensão e queda. Essas imagens são intercaladas com uma trilha sonora baseada em partituras de Bill Frisell e Henryk Gorecki e uma voz em off que introduz e contextualiza comentários sobre o funcionário incumbido dos registros autorais na Biblioteca do Congresso e seu fascínio pelo cinema, representado pelas cenas de uma mulher que ele vira, quando jovem, em um filme pornográfico ${ }^{3}$. Embora haja linearidade

\footnotetext{
${ }^{3}$ No entanto, como assinala o próprio Bill Morrison: "Em The film of her, nunca houve uma estrela pornô que inspirasse um arquivista a redescobrir uma coleção. [...] A questão é que eu estava à procura de um ponto da trama que teria alguma paixão, porque as razões que ele me dava, nas entrevistas, não eram convincentes; ele estava apenas maravilhado com o que estava lá embaixo. [...] Então, havia essa pergunta: ‘Qual foi o impulso para ele descobrir essa coisa?'”' (CAIN, 2006).
} 
entre as imagens que compõem o primeiro minuto de The film of her, é a noção de fragmento que articula o ritmo do filme, uma vez que a diversidade do material usado aponta para o fracasso do registro documental, quando o tempo exerce sobre ele sua força desorganizadora, como o próprio cineasta pontua, em um catálogo de retrospectiva de sua obra:

\footnotetext{
A imagem faz uma breve pausa diante da lâmpada do projetor, e depois segue em frente. Nossas vidas são acumulações de imagens efêmeras e momentos que nossa consciência constrói em uma realidade. Mal compreendemos o presente, ele é relegado ao passado, onde ele só existe na história subjetiva de cada indivíduo. As imagens podem ser pensadas como desejos ou memórias: ações que ocorrem na mente. O material do filme pode ser pensado como o corpo, o que permite que estes eventos possam ser vistos. Tal como os nossos corpos, este celuloide é um meio frágil e efêmero que pode se deteriorar de inúmeras maneiras. (CAIN, 2006).
}

A partir da concepção do cinema como arte de fragmentos e de ruínas, Bill Morrison dará forma ao seu filme mais conhecido, Decasia: the state of decay (2002). Em Decasia, Morrison está interessado não na preservação dos filmes, mas na sua deterioração. Para isso, ele reúne cenas de diversos filmes esquecidos na Biblioteca do Congresso Americano e em estado avançado de apodrecimento. Como esse fenômeno de decadência do material é algo natural, Morrison deu o título ao filme de Decasia: the state of decay. Este neologismo, Decasia, uma referência à relação entre música e imagem, que ocorre no filme Fantasia (Norman Ferguson et al, 1940), determina não apenas um significado que aponta para o fim, mas para o processo que é interrompido, pois o apodrecimento da película e aquilo que está registrado nela são colocados em suspensos, ao serem refilmados e reintegrados a um novo contexto, um longa-metragem, cujo tema é a deterioração da matéria e seu esquecimento. Cada imagem é um fragmento, pois se constitui de manchas, borrões, distorções, enfim, tudo aquilo que assinala sua deterioração e sua obliteração. As imagens em estado de decomposição, em Decasia, lembram, nesse sentido, aquilo que Deleuze (2007, p. 104) define como diagrama, ao analisar a obra de Francis Bacon: "o diagrama é, portanto, o conjunto operatório das linhas e zonas, dos traços e manchas 
assignificantes e não representativos". O diagrama, em Decasia, muitas vezes, surge fora de controle, pois ele se prolifera de maneira a ocupar toda a imagem, deixando-nos apenas fragmentos reconhecíveis. Tanto os corpos quanto a paisagem estão em desequilíbrio, "em estado de queda permanente; os planos caem uns sobre os outros" (DELEUZE, 2007, p. 119), de maneira que a imagem, aí, passa a ser "a forma imutável na qual se produz a mudança". (DELEUZE, 2005, p. 27). Sua duração é a de uma memória que não se prende a um ponto determinado no tempo, mas desmorona a partir do dilaceramento que provoca em si mesma, ao afirmar a precariedade que a mantém. Poderíamos pensar essa precariedade em termos de informe, sobre os quais Jacques Aumont dedica algumas observações:

O desejo de informe é coisa rara no cinema, onde reina, ao contrário, no mais das vezes, a obsessão da forma controlada. No máximo ele aparece ali, aqui e ali, na história dos filmes, em doses homeopáticas, e talvez vacinais, como que para melhor afastar a tentação. [...] A a-forma, o surgimento de alguma coisa que não ainda "secundarizada", que crie acontecimento, onde encontrá-la? Nunca no cinema inteiro, nunca sequer na escala de todo um filme, mas apenas em momentos particulares, frações de tempo ou frações de extensão, onde ocorre algo que o "grão-mestre das imagens" não havia previsto. (AUMONT, 2004, p. 209).

O informe, pensado não como uma negação, mas como o que contesta a forma, ao tornar visíveis as contradições da figuração em suas intermitências, é visto como exceção, algo que deve ser evitado por aquele que controla o filme. No entanto, a presença do informe, como ocorre em Decasia, não significa que não haja controle, pois há um manejo proposital do diagrama, possível de ser percebido pelas escolhas do diretor em intercalar uma imagem com outra, em repetir as cenas que lhe convêm. Na verdade, essa característica intencional do informe já havia sido formulada por Georges Bataille, quando ele amparou o termo em um dicionário cuja função seria a de anunciar as tarefas das palavras, em vez de apresentar os seus sentidos. (BATAILLE, 1970, p. 217). Nessa perspectiva, o informe assinala uma obsessão que se dá pela forma controlada, tanto que Bill Morrison se vale do uso de material deteriorado para a construção de outras 
obras suas.

Em seu filme The Mesmerist (2003), o cineasta se utiliza de duas cópias de The bells (1926), dirigido por James Young, uma intacta e outra danificada, para produzir uma obra na qual os contrastes entre a ruína e o que permanece ileso geram diferentes interpretações da narrativa, já que "a obliteração se torna representante de um estado de sonho ou, neste caso, um estado de realidade, e o filme intacto se torna um estado de sonho". (CAIN, 2006). Morrison se apropria, portanto, não apenas daquilo que foi esquecido, mas da própria dinâmica do esquecimento, no que se refere ao abandono das imagens que não cumprem a sua impressão de realidade, visto que dá outro significado à destruição causada pelo tempo, o de servir como elemento de construção de uma obra cinematográfica. Escolhem-se imagens cujas deformações causadas pelas reações químicas sobre a película de nitrato se mostram como possibilidades de aceitar-se a obliteração a partir de uma perspectiva estética. O tempo se torna, assim, uma espécie de raiz corrosiva, ao proliferar sobre a película, ocupando todos os espaços. No entanto, isso não quer dizer que o filme se configure em uma obra abstrata, mas sim, em uma espécie de conjugação do abstrato com o figurativo, mescla de representação e desfiguração. O tempo configura sua própria representação, que se torna encenável apenas no momento em que o cineasta determina o que pode ou não ser usado.

Em sua análise do informe, Aumont (2004 p. 209) chama a atenção para as características estéticas engendradas por ele: "momentos de surgimento, a plasticidade é sua marca; a cor, a violência de certo preto-e-branco, é seu veículo privilegiado, e sobretudo a cor em movimento, aquela que parece se soltar dos objetos para se tornar singular". Em Decasia, esses momentos de surgimento não são esporádicos, mas constantes, pois constituem, de acordo Böser (2007, p. 318), "a volatilidade de sua representação cinemática, ao refratar seu próprio contexto histórico das formas representacionais". É bom ressaltar que a apropriação realizada por Morrison sobre o material deteriorado rompe com as referências que possam ligar os fragmentos de filmes não só a um contexto histórico, mas também ao lugar de onde vieram. Tais fragmentos sobrevivem 
duplamente como vestígios, uma vez que rementem tanto a uma origem, agora apagada, esquecida, quanto à sua representação obliterada, incompleta.

O tempo, portanto, é o assunto principal dos filmes de Morrison. Ele se apresenta como reflexão histórica e como consciência de que tudo se coloca sobre um estado de perda. Nesse sentido, vida e morte, ao se entrelaçarem, oferecem-nos dois caminhos que têm no tempo seu eixo principal: a memória e o esquecimento. $O$ que vemos se forma a partir das ruínas de um presente deteriorado, cujos destroços se fazem visíveis pelas marcas que deixam nas superfícies da história. Tudo o que é visto, no filme de Morrison, já não existe mais, pois mesmo os borrões, reações químicas sobre a película cinematográfica, são memórias corroídas por aquilo que lhes é exterior.

No entanto, pode-se dizer que Decasia não é apenas uma meditação sobre o tempo, mas também sobre a morte. Nesse sentido, se existe um aspecto mórbido e melancólico abordado em seus filmes, é porque percebemos que a memória, ao ser aprisionada, mostra-se dilacerada pelo tempo. Decasia, nesse sentido, é um memento mori. Cada uma de suas imagens nos lembra de que um dia morreremos, apodreceremos e nossa memória se apagará. No entanto, o filme faz dessa podridão aquilo que nos fascina. Somos envolvidos pelas formas que desaparecem dando lugar a outras, pelo informe como determinação do incerto, do que foge às normas acadêmicas, às definições pré-concebidas. Esse informe, imagens que desabam, soterra corpos e objetos. Seria assim o papel principal desempenhado pela morte. $O$ que nos atraí está na maneira como essa morte se faz obscena, ao se deixar entrever nas aberturas dos corpos, do filme que contesta sua própria natureza.

O tempo que penetra o espaço fílmico se expõe como uma ausência representativa, pois essa memória reminiscente aponta para algo que, simultaneamente, existe e não está mais ali, o que se estabeleceria naquilo que Blanchot (2011, p. 280) define como presença cadavérica: "[...] a presença cadavérica estabelece uma relação entre aqui e parte nenhuma". O filme se realiza, assim, como o entre-lugar, já que o fora de campo, que nele se insinua, não é de um espaço imaginário, mas de um tempo que, de um espaço exterior, 
invade a película cinematografia, transformando-a em ruínas. Por isso, na montagem, não é mascarado ou disfarçado o fato de os fragmentos serem trechos de diferentes filmes, pois o que se quer é a disjunção e o padrão das formas inconstantes. Há, assim, uma obra que não é redutível à unidade, mas, segundo Blanchot (2010, p. 43):

\footnotetext{
Um arranjo de tipo novo, que não seria o de uma harmonia, de uma concórdia ou de uma conciliação, mas que aceitará a disjunção ou divergência como o centro infinito a partir do qual [...] uma relação deve estabelecer-se: um arranjo que não compõe, mas justapõe, isto é, deixa de fora uns dos outros os termos que vêm em relação, respeitando e preservando essa exterioridade e essa distância como o princípio sempre destituído - de toda significação.
}

Teríamos isso que próprio Blanchot nomeia como "arranjo ao nível da desordem", pois as imagens que compõem Decasia não são mais restos, mas fraturas que o tempo abre em interrupção. O salto de uma imagem a outra se dá pela sua desintegração, pelo entrelaçamento das ruínas que o tempo provoca sobre a película. Dessa forma, as ruínas criam um terreno movediço, onde a escavação altera a relação do presente com o passado. As imagens de Decasia como formas fragmentadas se realizam, portanto, "senão naquilo que estará irremediavelmente perdido no instante seguinte". (BENJAMIN, 2006, p. 515). E o que se perde, na imagem, é tanto o seu contexto histórico quanto a sua configuração na clareza e na discernibilidade. No entanto, mesmo quando parece não haver mais imagem, há alguma coisa, há ainda corpos que subsistem entre as ruínas. Como bem observa Habib (2006, p. 123):

\footnotetext{
Quando um objeto perde sua integridade física, sua forma e as coordenadas que the permitem atualizar ou realizar um certo número de ações ou tarefas, nós dizemos que esta coisa está em ruínas. Mas é por cair na ruína que ele aparece como uma imagem, uma vez que seu uso deixou de substituí-lo.
}

As imagens deslocadas, quando inseridas em um novo contexto, convidamnos, conforme Wees (1993, p. 11), "[...] a reconhecê-las como found footage, imagens recicladas, e devido a essa autorreferencialidade, elas encorajam uma leitura mais analítica do que o filme originalmente recebeu". Assim, a desordem 
possibilita que novas significações surjam no instante em que a montagem questiona a representação cinematográfica, sua realidade ilusória, ou seja, o fato de um filme ser constituído de pedaços de celuloide.

Bill Morrison propositalmente alterna trechos de documentários, longas e curtas-metragens, cine jornais, entre outros gêneros cinematográficos, sem fazer uma distinção clara entre eles. A aglutinação desse material heterogêneo nos leva, a princípio, a compará-lo com $A$ movie, de Bruce Conner. Mas, enquanto $A$ movie lida com os fragmentos descartados pela indústria cinematográfica e deixa em evidência os fotogramas com os sinais de manipulação da montagem, de maneira a criticar o próprio conceito do que é ou não é cinema, Decasia, a partir da dialética entre memória e esquecimento, configura a destruição como parte de um processo criativo, no qual a dissolução química permite que uma imagem se torne outra, no momento em que suas disjunções são cobertas pelas marcas de deterioração.

Essa opção estética é o que talvez aprofunde as diferenças entre Decasia e um filme como Lyrical nitrate (1990), de Peter Delpeut, no qual é possível perceber que a apropriação dos fragmentos de filmes em nitrato mantém-se a partir do agrupamento em sequências e da legibilidade que as compõem. Uma sequência que aparece inteira, a dos mineiros soterrados, em Lyrical nitrate, surge, em Decasia, fragmentada e interpolada a trechos de outros filmes. Podemos observar, assim, que o que une as sequências de Decasia é o ritmo estabelecido pelo movimento de corrosão sobre a película de nitrato, a partir do qual o drama passa a ser a instabilidade que o tempo afirma sobre as coisas visíveis. Os vazios da imagem são preenchidos pela desordem química, pelas marcas que o tempo deixa ao corroer corpos, paisagens, objetos, tornando-os, em vários momentos do filme, irreconhecíveis.

Como uma das tarefas do informe passa pela desarticulação da forma, não é de se estranhar que, de acordo com Krauss (2002, p. 171), "a sedução pela podridão e pela decomposição [...] é a própria essência do informe”. E, nesse aspecto, talvez resida outra diferença entre o filme de Bill Morrison e o de Peter Delpeut, que é a maneira como cada um lida com a nostalgia. De acordo com 
Boym (2001, p. 49):

\begin{abstract}
Restauração (de re-staure - re-estabelecimento) significa um retorno à stasis original, ao momento anterior ao colapso. O passado para a nostalgia restaurativa é um valor para o presente; o passado não é a duração, mas um instantâneo perfeito. Além disso, o passado não precisa revelar quaisquer sinais de decomposição; mas ser pintado com tinta fresca em sua "imagem original" e permanecer eternamente jovem. Nostalgia reflexiva diz mais respeito a um tempo histórico e individual, com a irrevogabilidade da finitude passada e humana. Re-flexão sugere uma nova flexibilidade, não o restabelecimento da stasis. $O$ foco aqui não é sobre a recuperação do que é percebido como uma verdade absoluta, mas a meditação sobre a história e passagem do tempo.
\end{abstract}

Em sua análise de Decasia, Jaimie Baron aponta para esses dois tipos de nostalgia que o filme poderia criar, dependendo da forma como lançamos o olhar sobre ele. Para Baron (2014, p. 130), Decasia, ao se constituir de fragmentos, a princípio, geraria um desejo de ter acesso ao todo, de reconstruir um passado que não existe mais, o que aproximaria o filme de uma nostalgia restaurativa. No entanto, esta hipótese logo é abandonada em favor de uma nostalgia reflexiva, visto que "ao invés de tentar restaurar as cópias de nitrato de algum estado original (e inatingível), Morrison nos oferece a ruína de desintegração, o fragmento presente de um passado que nunca pode ser ressuscitado". (BARON, 2014, p. 130). Embora Peter Delpeut, em Lyrical nitrate, não utilize técnicas de restauração, a forma como o filme foi organizado, capítulos com títulos, impõe uma perspectiva nostálgica, pois seus fragmentos são agrupados em torno de evocações à própria coleção de que faziam parte, o catálogo de distribuição que Jean Desmet exibia em seu cinema entre 1905 e 1920, na Holanda. Cada capítulo assinala, através de seu título, tanto o local onde esses filmes foram exibidos, o cinema Parisien, quanto suas temáticas, determinando, assim, modos de se assistir a esses fragmentos. O último capítulo, intitulado "And forgetting", é o único que se constitui, em quase sua totalidade, de trechos de um filme deteriorado. No entanto, exatamente porque está no final, ele sugere o passado como restos de uma memória evocada à custa da nostalgia. O esquecimento seria, nesse sentido, parte de um desenvolvimento, cujo fim está traçado desde seu início. A 
disparidade temporal torna-se, dessa forma, amenizada, pois os fragmentos são justapostos a partir da linearidade de uma narrativa que progride à medida que a nostalgia ganha cada vez mais força. A sequência deteriorada do filme sobre Adão e Eva expulsos do paraíso encontra respaldo na interpretação do cinema como lugar utópico, onde a ausência de tempo seria a libertação das fantasias.

Diferente de Peter Delpeut, Morrison não organiza seu material em capítulos ou por meio de títulos. A disparidade é propositalmente buscada e uma das estratégias de que Bill Morrison se utiliza para isso é a manipulação do tempo em seu filme. Ao contrário do que ocorre em The film of her, no qual podemos perceber variações de velocidade que a montagem imprime sobre os trechos selecionados, Morrison optou por uma velocidade de exposição de quadros constante em Decasia. Ao montar todos os fragmentos em slow motion, ele permitiu que a deformação dos corpos e dos objetos se tornasse visível para o espectador. Como Morrison se vale de obras de outros cineastas, ele se utiliza de um "slow de trucagem", o que significa dizer que, ao contrário do "slow de câmera", em que o efeito de câmera lenta se dá no momento da filmagem em uma cadência maior, ele, ao tratar as imagens, multiplicou as cadências originais. Por exemplo, um filme com a cadência de 24 quadros por segundo pode ter sido duplicado, passando a ter 48 quadros por segundo, para, assim, nos dar a impressão de câmera lenta. O efeito dessa técnica, em Decasia, é que a decomposição da imagem assume duplo sentido. Observarmos, ao mesmo tempo, a deterioração da película e a análise desse processo, pois o slow motion se oferece como possibilidade de investigar as reações químicas a partir das estruturas abstratas que impregnam o filme, o que talvez fosse imperceptível, caso os fragmentos tivessem sido exibidos em suas cadências originais. De acordo com Bellour (1997, p. 146):

Os instantes "neutros" da decomposição são aproximados, só pelo trabalho do olhar que subentendem, dos instantes privilegiados em que essa decomposição se tematiza em certos gestos e de certos momentos. Do mesmo modo que um olhar disperso se concentra de novo sobre o que captura. 
Embora Bellour refira-se às imagens congeladas que se formam a partir da relação entre cinema e fotografia, sua análise sobre a suspensão do tempo compreende uma interpretação que pode ser aplicada a Decasia, pois "a imagem excessivamente fixa, a suspensão do tempo demasiadamente visível, remete-nos inexoravelmente à perda e à morte". (BELLOUR, 1997, p. 152). Em Decasia, poderíamos arriscar a dizer que o tempo se torna visível não só pela destruição que ele acarreta sobre a película, mas pelo ritmo que estabelece, que é o de perda, uma vez que o "slow de trucagem" oferece a sensação de movimento falho, de intermitência.

Estaríamos, assim, entrando nos domínios daquilo que Deleuze definiu como imagem-cristal. No conceito de imagem-cristal, que Deleuze desenvolve a partir de sua leitura da obra de Henri Bergson:

O passado não sucede ao presente que ele não é mais, ele coexiste com o presente que foi. O presente é a imagem atual, e seu passado contemporâneo é a imagem virtual, a imagem especular. Segundo Bergson, a "paramnésia" (ilusão de déjà-vu, de já-vivido) nada mais faz que tornar sensível esta evidência: há uma lembrança do presente, contemporânea do próprio presente, tão colada a este quanto um papel ao ator. (DELEUZE, 2005, p. 99).

Por meio do slow motion, as imagens de Decasia desdobram-se, cindem-se, em presente e passado. Assistimos à junção entre o límpido e o opaco, às imagens se cristalizarem no amorfo, ao passado lançado no presente, desfazendo-o à medida que volta a constitui-lo. O informe torna-se, apropriandonos das palavras Deleuze (2005, p. 103), "o ponto de indiscerniblidade de duas imagens distintas", pois, como imagem-cristal, ele é o abismamento, imagens de um presente e de um passado, de um atual e de um virtual, que dilaceram um ao outro, e nunca param de se reconstituir.

Dessa forma, a uniformidade do ritmo criado pelo slow motion se mostra, na verdade, um tempo no qual a decomposição impera, já que ela se coloca de maneira ininterrupta entre o passado que se cristaliza e o presente que oscila no passado. $O$ fracasso da imagem é encarado como um meio de levar essa 
decomposição a proliferar-se em espelhos, nos quais o que se reflete é a dissolução das distinções. Por isso, os corpos, em Decasia, são repetidas vezes tragados, soterrados, pelas marcas de deterioração que se espalham sobre o filme ou estão em luta contra elas, em uma batalha dramática, de maneira que não podemos distingui-los mais dos espaços que os cercam. Tais encontros assumem conotações quase existenciais, já que os corpos estão sob a ameaça de serem apagados, devorados por aquilo que os rodeia, como ocorre na famosa sequência do boxeador. É interessante notar que foi com base nesse trecho que o filme ganhou forma, como relata o próprio Bill Morrison:

\footnotetext{
Decasia foi uma comissão feita a Michael para escrever uma nova sinfonia. Eles tinham fundos culturais europeus o suficiente para que pudessem dar suporte visual à música. Nós havíamos colaborado com Michael antes. E eu tinha visto essas imagens. Eu tinha visitado recentemente um arquivo e vi este boxeador aparentemente golpeando um saco de box. Mas o saco explodia nessa bolha amorfa de ruína e pareceu uma imagem muito poderosa para mim, então eu sugeri construir a coisa toda em torno desta imagem, esta ideia de ruína e combate à ruína. (CAIN, 2006).
}

Conforme assinala Bill Morrison, na citação acima, Decasia foi concebido como um trabalho em conjunto com o músico Michael Gordon. Parte do efeito hipnótico que o filme gera não se restringe apenas ao seu plano visual, mas à maneira como sua trilha sonora se entrelaça aos aspectos que foram pontuados sobre o filme até este momento. Se, em The film of her, temos uma voz em off a tecer comentários acerca das imagens que vemos, em Decasia, "o próprio tempo se torna sonoro". (DELEUZE, 2005, p. 116). Imagem e som refletem-se, pois o ritmo do slow motion de Bill Morrison encontra-se com a da partitura de Michael Gordon, de tal forma que, em Decasia, tempo e música entrecruzam-se, fazem-se, desfazem-se. As imagens surgem, nesse entre-dois, de maneira, a princípio, caótica, sem relação umas com as outras. Decasia começa com a imagem de um dançarino sufi em transe. Ritmados pela trilha sonora, rolos de filmes continuam a dança e mergulham em uma piscina de emulsão, de onde um borrão, uma espécie de nuvem química, invade o filme. Como processo inverso da revelação fotográfica, o 
líquido, ao invés de revelar, apaga o registro, corrói e destrói as imagens que há pouco nos atraíam. O tempo, agora, se faz outro, a música parece se intensificar. Já não se vê nada além de manchas e borrões. É possível perceber que alguma coisa aparece, uma espécie de azulejo. Surge, então, uma mulher oriental, que desaparece por uma porta, dando lugar ao mar e às rochas. Os borrões criam ondas violentas que se quebram na praia. A última onda transcende para a próxima sequência de imagens, na qual novamente nada é visto além de sombras informes.

Parte da dificuldade de se tentar resumir Decasia ocorre devido ao fato de o filme se constituir de inúmeros fragmentos de origens e fins bem distintos, como pode ser percebido na descrição que fizemos. No entanto, é possível pensar que a convergência de tais fragmentos tem no caos o seu catalizador. No entre-dois, conforme Deleuze e Guattari (1997, p. 119):

O caos torna-se ritmo, não necessariamente, mas tem uma chance de tornar-se ritmo. O caos não é o contrário do ritmo, é antes o meio de todos os meios. Há ritmo desde que haja passagem transcodificada de um para outro meio, comunicação de meios, coordenação de espaços-tempos heterogêneos. O esgotamento, a morte, a intrusão ganham ritmos.

Em Decasia, a heterogenia é o que abre espaço tanto para a diversidade de imagens quanto para o ritmo que, nelas, constrói-se. $O$ caos que as imagens geram, quando intercaladas, é transformado em ritmo, pois imagem e música convergem para um estado crítico, no qual a repetição se assinala como diferença. A partitura minimalista escrita por Michael Gordon se ampara nesse estado crítico, a partir do qual continuidade e descontinuidade se constituem como um tempo em decomposição, no qual as ruínas das imagens encontram na música não apenas o seu espelhamento, mas o seu excesso. No entanto, o resíduo, que surge da relação entre imagem e música, não deve ser pensado como descartável, mas violência que rompe com a ordem, ao afirmar, na redundância, a impossibilidade de se reconstituir o passado e se prender a um presente. Esse comprometimento com a desordem, com o que foge do tom, é assinalado por Michael Gordon, ao imaginar um piano que não tivesse sido 
afinado por 20 anos e como seria o equivalente disso na forma de uma orquestra: "então, aqui estão músicos clássicos que passaram a vida inteira tentando tocar perfeitamente no tom, agora tentando tocar perfeitamente fora do tom, o que é uma tarefa e tanto". (GORDON, 2001). O movimento de desordem, que está tanto na música quanto na imagem, é o que faz com Decasia se diferencie tanto de Fantasia. A relação entre imagem e música, em Fantasia, acontece em decorrência da unidade, da harmonia, da possibilidade de sincronizar os acontecimentos da animação com a música, de maneira a eliminar as incongruências.

Em Decasia, a sequência do dançarino sufi, que aparece no início do filme, intacta, ressurge, no final, parcialmente deteriorada, como se nem mesmo o transe, no qual ele está imerso, pudesse ser invulnerável ao tempo. As desintegrações das imagens finais de Decasia tornam mais visível esse caráter informe do tempo, no qual a música, a partir de suas dissonâncias, incongruências e repetições, abre-se tanto às multiplicidades de imagens que o filme carrega quanto àquilo que $\mathrm{o}$ invade: $\mathrm{o}$ tempo e a destruição. $O$ informe, pensado como a oscilação entre a forma e a não-forma, torna-se o domínio da heterogenia. Assim, não causará estranhamento algum, se assistirmos a Decasia com atenção, para percebermos que a primeira imagem informe a aparecer no filme é exatamente a de uma nuvem de vapores. Sem uma origem definida, ela invade o espaço do filme. Durante poucos segundos, não há nada a não ser uma nuvem. Mas é a partir dela que se tem início a precariedade, o estado de ruína, de decadência que dominará todo filme. É como se essa nuvem, amorfa, indefinida, prestes a se desfazer, produzisse uma convulsão da imagem, diante da qual os limites desmoronassem e o cinema passasse a narrar a história de seu reverso e sua impermanência.

\section{Bibliografia}

AUMONT, Jacques. O olho interminável: cinema e pintura. São Paulo: Cosac \& Naify, 2004.

BARON, Jaime. The archive effect: found footage and the audiovisual experience of history. London; New York: Routledge, 2014. 
BATAILLE, Georges. Oeuvres Completes V. Paris: Gallimard, 1970.

BELLOUR, Raymond. Entre-imagens. Campinas: Papirus, 1997.

BENJAMIN, Walter. Passagens. Belo Horizonte: Editora UFMG, 2006.

BLANCHOT, Maurice. A conversa infinita 3: a ausência de livro, o neutro, o fragmentário. São Paulo: Escuta, 2010.

BLANCHOT, Maurice. O espaço literário. Rio de Janeiro: Editora Rocco, 1987.

BÖSER, Ursula. "Inscriptions of light and the 'calligraphy of decay': volatile representation in Bill Morrison's Decasia". In: AVANT-GARDE FILM. Edited by Alexander Graf and Dietrich Scheunemann. Amsterdam; New York: Rodopi, 2007. BOYM, Svetlana. The future of nostalgia. New York: Basic Books, 2001.

CAIN, Maximilian Le. Trajectories of Decay: An Interview with Bill Morrison. Special dossiers: the films of Bill Morrison. Issue 41. 2006. Disponível em: http://sensesofcinema.com/2006/41/bill-morrison-interview/. Acessado em: $01 \mathrm{de}$ setembro de 2014.

COSTA, Flávia Cesarino. "Primeiro Cinema". In: MASCARELLO, Fernando (Org.). História do cinema mundial. $7^{\text {a }}$ ed. Campinas: Papirus, 2012.

DELEUZE, Gilles. A imagem-tempo. São Paulo: Brasiliense, 2005.

DELEUZE, Gilles. Francis Bacon: a lógica da sensação. Rio de Janeiro: Jorge Zahar Editor, 2007.

DELEUZE, Gilles; GUATTARI, Felix. Mil platôs: capitalismo e esquizofrenia. São Paulo: Ed. 34, 1997. v. 4.

GORDON, Michael. Decasia: programme note. 2001. Disponível em: www.musicsalesclassical.com/composer/work/28219. Acessado em: 17 de junho de 2015.

HABIB, André. "Ruin, Archive, and the Time of Cinema: Peter Delpeut's Lyrical Nitrate". SubStance, v. 35, n. 2, 2006, 120-139.

KRAUSS, Rosalind. O fotográfico. Barcelona: Editorial Gustavo Gili S. A., 2002. VERRONE, William. The Avant-Garde Feature Film: a critical history. Jefferson: McFarland \& Company, 2012.

WEES, William C. Recycled images: the art and politics of found footage films. New York: Anthology Film Archives, 1993. 


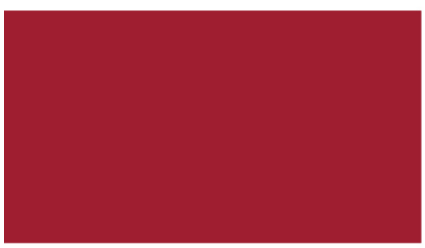

rebeca

Revista Brasileira
de Estudos de
Cinema
e Audiovisual

